\title{
Non-Invasive, Fast and Reliable Assessment of Age- And Gender-Related Pancreas and Liver Fat Content in Completely Healthy Individuals: Modified Dixon Method with 3 Tesla Magnetic Resonance Imaging
}

Feyza Yilmaz*

Department of Radiology, Gaziantep University School of Medicine, Gaziantep, Turkey

Received: August 28, 2018; Accepted: September 10, 2018; Published: September 12, 2018

*Corresponding author: Feyza Yilmaz, Department of Radiology, Gaziantep University School of Medicine, Gaziantep, Turkey, Tel no: +905322182619; E-mail: feyzagelebekyilmaz@hotmail.com

\begin{abstract}
Objective: Acquiring the content of liver fat related to age and gender, and iron signal time as well as fat content values in pancreas and muscle tissue in healthy subjects with normal body mass index (BMI), by using Modified Dixon (mDixon) magnetic resonance imaging.

Method: The study enrolled a total of 62 patients aged between 20-62 years including 35 male (56.5\%) and 27 female (43.5) patients as healthy liver donors who had normal BMI (18.2 - $25.7 \mathrm{~kg} / \mathrm{m} 2)$ according to Modified Dixon quantification (mDixon quant) sequence in 3 Tesla MR device. Fat content (\%) and signal time value for iron (millisecond) in the liver tissue and fat content (\%) in pancreas and muscle tissue were automatically quantified in the relevant areas through images. For normalization, muscle tissue was measured for the value of iron signal time. Liver segment VI, head, body and tail parts of pancreas, and two paraspinal muscles (multifidus) in the same section were quantified. Multivariate generalized linear models were used to test significant differences in fat contents and iron signal time values between age subgroups.

Results: Mean fat content in the liver was measured as $3.06 \pm 1.06 \%$ with value of iron signal time as $23.32 \pm 3.27 \mathrm{msec}$, and mean fat content in the pancreas was measured as $2.87 \pm 1.67 \%$, mean fat content in the muscle tissue as $3.62 \pm 2.04 \%$ and value of iron signal time as $27.58 \pm 3.16$ msec. Mean liver fat content did not show a significant difference between female (2.89 \pm 1.19$)$ and male patients $(3.19 \pm 0.94)$ (p-value: $0.252 /$ 0.936). Differences in liver fat contents between age subgroups were not significant for female vs. male patients (2.91 \pm 0.88 vs. $2.82 \pm 0.90$ (2029 years), $2.69 \pm 1.77$ vs. $3.24 \pm 0.81$ (30-39 years), $2.56 \pm 1.00$ vs. $3.21 \pm 1.09$ ( $40-49$ years) and $3.37 \pm 1.44$ vs. $3.42 \pm 0.99$ (50-62 years). While there was a positive correlation between the age and fat contents in pancreas $(r=0.385, p=0.022)$ and muscle $(r=0.697$, $p=0.001)$ in male patients, a positive correlation was seen only between age and muscle fat content in female patients $(r=0,458, p=0,016)$. Along with BMI values within normal range, BMI was found to be positively correlated with liver $(r=0.382, p=0.024)$ and muscle fat contents $(r=0.380, p=0.024)$ only in male patients. A mild negative correlation ( $\mathrm{r}=-0,420, \mathrm{p}=0.029)$ and a strong negative correlation $(\mathrm{r}=-0,617, \mathrm{p}=0.001)$ were seen in women and men, respectively, between mean fat content and iron signal time of liver. There was a mild positive correlation between liver fat content and muscle fat content in men $(\mathrm{r}=0,409, \mathrm{p}=0.015)$.
\end{abstract}

Conclusion: Mean MR-based liver fate content did not demonstrate a significant difference between women and men, and did not change with age in women vs. men. While the content of pancreatic and muscular fat increased in male subjects with age, only the content of muscular fat increased with age in female patients. The more BMI increased, the more the contents of liver and muscle fat increased in male patients. It was detected that iron load amount of liver became lower as the content of liver fat increased.

Key Words: Fatty Liver Disease; Hepatic Iron Overload; Liver; Magnetic Resonance Imaging

\section{Introduction}

Fatty liver and iron build-up are the common reasons of chronic parenchymal liver disease [1, 2]. Underlying pathogenic mechanisms resulting in diffuse parenchymal liver disease are countless, and hepatocellular damage and cell death cause hepatic fibrosis and primary liver cancer [3].

Increased pancreatic fat content may be observed in various local pathological processes such as pancreatic cancer or pancreatitis, and moreover, it is thought to develop due to reduced pancreatic volume and increased pancreatic fat content in patients particularly with metabolic diseases and impaired glucose metabolism [4-6].

Therefore, early and proper diagnosis of parenchymal chronic diseases is very important for initiation and follow-up of treatment before irreversible organ damage occurs. Biopsy is the most correct technique for diagnosis of substance accumulation syndromes and related diseases [7]. However, liver biopsy of percutaneous random sample is an invasive procedure that has pre- and post-procedure risks and may cause sampling errors particularly from hepatic metabolite beds which are heterogeneously distributed [8]. 

Magnetic Resonance Imaging

Magnetic resonance imaging (MRI) is used for detection of metabolites in parenchymal liver disease associated particularly with intrahepatic lipids and iron ions by making use of chemical shift and magnetic susceptibility effects [9]. The presence of large quantities of lipid molecules in hepatocytes causes variations in resonance frequency. Echo timing in "in-phase" and "outof-phase" states allows for the detection of lipid molecules in contrast phase images by creating areas of relative signal loss [10]. On the contrary, the presence of iron leads to overall signal loss due to local magnetic field inhomogeneities induced associated with magnetic susceptibility by ion particles causing signal loss in in-phase images compared to out-of-phase images depending on longer echo times [11]. Fat content in organs is measured this way through an imaging method called Proton density fat fraction (PDFF) measurement calculated in percentages. And iron is measured in milliseconds on the basis of $\mathrm{T} 2 *$ images calculated with increased TE times.

As PDFF and $2^{*}$ values are acquired by different sequences, a method called modified DIXON has been developed to independently measure fat and iron contents in the organs with a single capture. This method scans the whole liver in a single breath-hold time and provides fat-iron quantifications in one sequence [12]. Recent studies have shown that PDFF and T2* MR imaging results through modified Dixon reconstruction have higher accuracy than standard histopathological evaluations and therefore, it is being increasingly used today for quantifying liver fat and iron [13].

Information on normal hepatic, pancreatic fat and iron content in certain age groups based on MRI might be helpful in scanning and risk prediction in liver and pancreas diseases presenting with especially substance accumulation by primarily using correct age-related reference values. Our study aimed to define reference standards of age- and gender-related liver and pancreatic fat content and values of iron signal time in normal, completely healthy donors scanned as liver donors by quantifying fat and iron content in liver as well as fat content in pancreas and muscle retrospectively in modified DIXON quant sequence with 3.0 Tesla MRI devices.

\section{Materials and Method}

This retrospective study was conducted by assessing images of completely healthy donor candidates who had MRI scans for steatosis evaluation of liver donor candidates between 20112018. 62 healthy liver donors aged between 20-62 years were enrolled in the study including seven men vs. 10 women for 20 29 age range, 10 men vs. five women for 30-39 age range, 10 men vs. six women for 40-49 age range and eight men vs. six women for $>=50$ years (totally 27 women; mean age, $37.96 \pm 13.42$ years; 35 men; mean age, $42.29 \pm 14.73$ years). Inclusion criteria were: a) normal BMI (18.2 - $25.7 \mathrm{~kg} / \mathrm{m} 2)$; b) being in the age bracket of 20-62; c); being healthy. Exclusion criteria were: a) systemic diseases (chronic obstructive pulmonary diseases, diabetes, metabolic diseases, rheumatological disorders, tumors, chronic pain syndrome); b) vascular problems (coronary heart disease, peripheral artery disease); c) alcoholism, drug use. As the cases were donor candidates, they underwent anamnesis, examination and tests. Age, height and weight of each case were determined and their BMI values were calculated.

\section{Data Collection and Analysis}

All MR examinations were performed on the 3.0 Tesla MRI devices (Ingenia, Philips Healthcare, Best, the Netherlands). The subjects were given supine positions with both arms at the sides. A 32-channel posterior coil integrated into examination couch and two 16-channel coils were used for receiving signal.

For liver fat quantification and $\mathrm{T} 2 *$ mapping, a BH 3D multiple echo GRE sequence (mDixon-Quant, Philips Medical systems, Best, the Netherlands), based on the mDixon technique, was performed using the following parameters: a $360 \times 327 \mathrm{~mm} 2$ field of view, $144 \times 131$ matrix, $6 \mathrm{~mm}$ slice thickness $(100 \%$ interpolation), 67 slices, 3-degree flip angle, $2346 \pm 125 \mathrm{kHz}$ receiver bandwidth, time to repetition: $5.6 \mathrm{msec}$, 6 echoes (initial time to echo: $0.95 \mathrm{msec}$, interval of TE: $0.7 \mathrm{msec}$ ). The sequence utilized a low flip angle, multi-echo, multi-peak method including $\mathrm{T}^{*}$ and eddy current compensation for accurate and reproducible fat quantification in a single breath hold time. mDixon-Quant (Philips Medical systems) automatically generated a fat fraction map and a T2* map. MR images of upper abdomen including hepatic, pancreatic and paraspinal muscle groups were used for this study. The images generated were assessed in work station of MR device. In PDFF and T2* images acquired from mDIXON sequence, three quantifications from liver segment VI, totally three quantifications including one from each of head, body and tail parts of pancreas and two quantifications from both paraspinal muscles (multifidus) in the same section were obtained by placing approximately $1.5 \mathrm{~cm}$ areas (ROI). Quantifications were acquired from areas not including the veins, bile ducts or areas with artifact in the liver parenchyma while quantifications from the pancreas were acquired by avoiding the fat around the pancreatic duct and the organ as much as possible. In these areas, PDFF values were provided in percentages and similarly, iron values were provided as $\mathrm{T} 2 *$ times in milliseconds by the device automatically (Figure 1). Moreover, by measuring T2* times and PDFF values in percentages from both paraspinal muscle groups in the same section, $\mathrm{T} 2 *$ times were compared also with liver values for normalization.

\section{Statistical analysis}

Normal distribution of numerical variables was tested by the Shapiro-Wilk test. The Student's t-test was used in the comparison of normally distributed numerical variables between both groups, and the Mann-Whitney U test was used to compare numerical variables that were not distributed normally between both groups. ANOVA and LSD multiple comparison tests were used to compare numerical variables with normal distribution between four groups, whereas the Kruskal-Wallis and Allpairwise tests were used for the comparison of variables with non-normal distribution between four groups. The correlations between numerical variables were tested using Spearman's 
a)

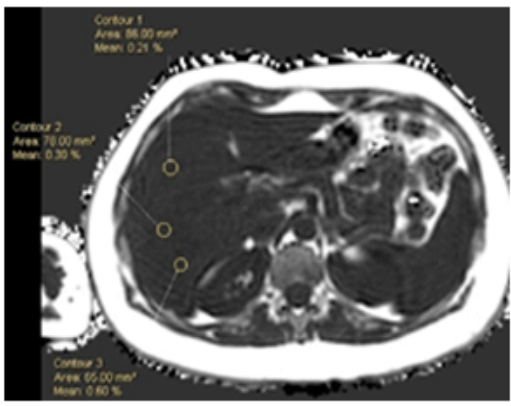

b)

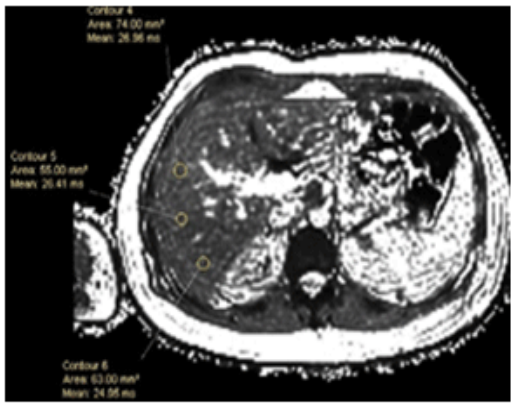

c)

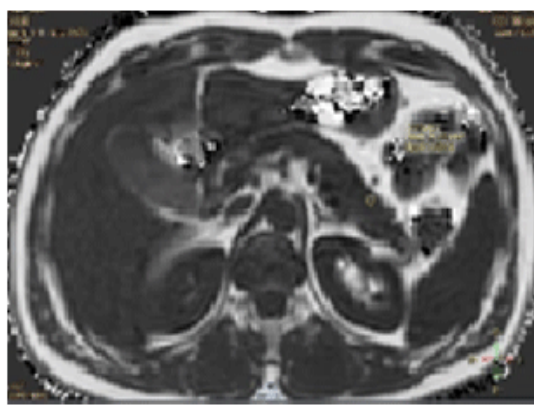

d)

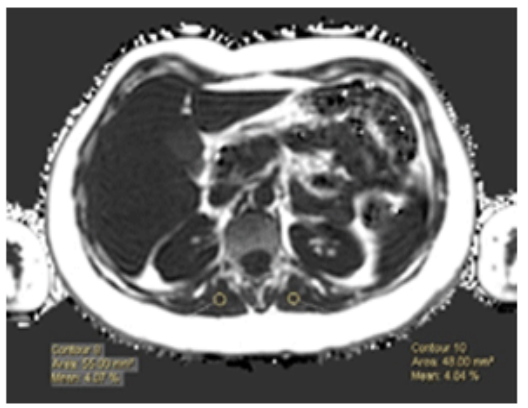

e)

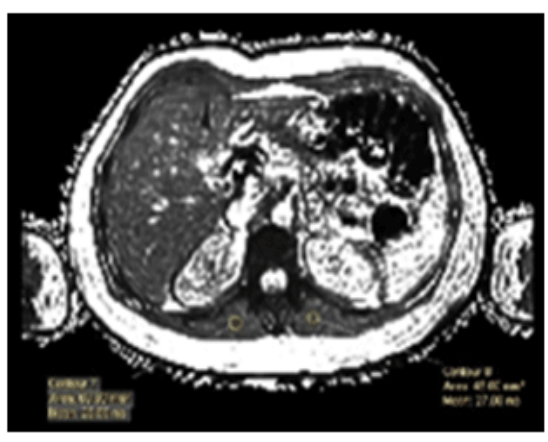

Figure 1: PDFF and T2* images generated by mDIXON sequence. a) percentage of liver PDFF, b) liver T2* in msec, c) percentage of pancreas PDFF, d) percentage of PDFF and e) muscle $\mathrm{T} 2 *$ in msec

rank correlation coefficient. Definitive statistics were provided with mean \pm standard deviation for numerical variables, and in numbers and percentages for categorical variables. SPSS 22.0 version for Windows was used in the analyses. $\mathrm{P}<0.05$ value was accepted as significant.

Results

\begin{tabular}{|c|c|c|c|c|c|}
\hline \multicolumn{2}{|l|}{} & \multicolumn{2}{|c|}{} \\
\hline AGble 1 & N & Minimum & Maximum & Mean & Std. Deviation \\
\hline BMI & 62 & 20.0 & 62.0 & 40.403 & 14.2247 \\
\hline LIVER fat avg & 62 & 17.6 & 25.9 & 23.499 & 2.7680 \\
\hline LIVER FE avg & 62 & 0.3 & 5.6 & 3.064 & 1.0607 \\
\hline PANC fat avg & 62 & 18.4 & 35.6 & 23.329 & 3.2664 \\
\hline muscle fat avg & 62 & 0.4 & 8.9 & 2.867 & 1.6665 \\
\hline MUSCLE FE avg & 62 & 0.5 & 8.8 & 3.622 & 2.0395 \\
\hline
\end{tabular}

Mean fat content in the liver was measured as $3.06 \pm 1.06 \%$ with value of iron signal time as $23.32 \pm 3.27 \mathrm{msec}$, and mean fat content in the pancreas was measured as $2.87 \pm 1.67 \%$, mean fat content in the muscle tissue as $3.62 \pm 2.04 \%$ and value of iron signal time as $27.58 \pm 3.16 \mathrm{msec}$ (Table 1 ).

Citation: Feyza Y (2018) Non-Invasive, Fast and Reliable Assessment of Age- And Gender-Related Pancreas and Liver Fat Content in Completely Healthy Individuals: Modified Dixon Method with 3 Tesla Magnetic Resonance Imaging. Gastroenterol Pancreatol Liver Page 3 of 9 
Table 2: Mean hepatic PDDF values (\%) based on age groups and gender

\begin{tabular}{|c|c|c|c|c|}
\hline & & \multicolumn{2}{|c|}{ Gender } & \multirow[b]{3}{*}{$\mathbf{P}$} \\
\hline & & $\mathbf{M}$ & $\mathbf{F}$ & \\
\hline & & LIVER fat avg & LIVER fat avg & \\
\hline \multirow{4}{*}{$\begin{array}{c}\text { Age } \\
\text { group }\end{array}$} & $20-29$ & $2.82 \pm 0.90$ & $2.91 \pm 0.88$ & 0.598 \\
\hline & $30-39$ & $3.24 \pm 0.81$ & $2.69 \pm 1.77$ & 0.727 \\
\hline & $>=50$ & $3.42 \pm 0.99$ & $3.37 \pm 1.44$ & 0.766 \\
\hline & $\mathrm{P}$ & 0.679 & 0.692 & \\
\hline
\end{tabular}

Mean hepatic PDFF value in all age groups between 20-62 years was $2.89 \pm 1.19 \%$ for women and $3.19 \pm 0.94 \%$ for men $(p=0.277$ ). Hepatic PDFF value did not show a significant difference based on gender or a correlation between the age groups (Table 2).

Table 3: Mean pancreatic PDDF (\%) values based on age groups and gender

\begin{tabular}{|c|c|c|c|c|}
\hline & & \multicolumn{2}{|c|}{ Gender } & \multirow[b]{3}{*}{$\mathbf{P}$} \\
\hline & & $\mathbf{M}$ & $\mathbf{F}$ & \\
\hline & & PANC fat avg & PANC fat avg & \\
\hline \multirow{5}{*}{ Age group } & $20-29$ & $1.92 \pm 1.00$ & $2.80 \pm 1.45$ & 0.230 \\
\hline & $30-39$ & $3.10 \pm 1.53$ & $2.84 \pm 1.95$ & 0.768 \\
\hline & $40-49$ & $2.65 \pm 1.76$ & $2.05 \pm 1.07$ & 0.875 \\
\hline & $>=50$ & $4.62 \pm 2.19$ & $2.52 \pm 0.85$ & $0.013^{*}$ \\
\hline & $\mathrm{P}$ & $0.027^{*}$ & 0.876 & \\
\hline
\end{tabular}

Mean pancreatic PDFF value in all ages between 20-62 years was $2.58 \pm 1.33$ and $3.09 \pm 1.87$, respectively, for women and men. Pancreatic PDFF values showed a significant difference between genders only when $>=50$, and pancreatic fat content was higher in men than women in this age group

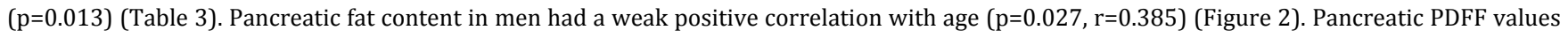
did not demonstrate a significant difference based on localization when compared with head, body and tail parts.

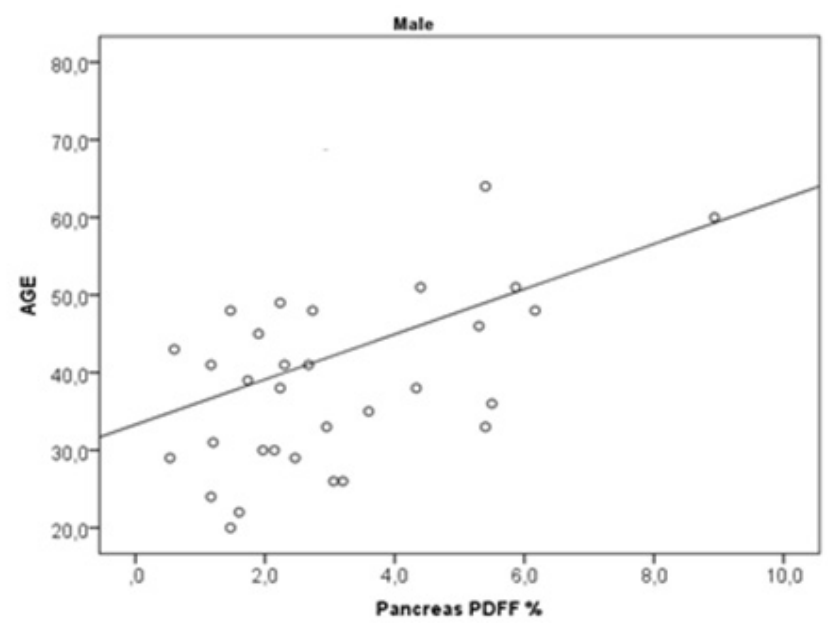

Figure 2: Correlation between age groups and pancreatic PDFF percentage in men 
Table 4: Mean muscular PDDF (\%) values based on age groups and gender

\begin{tabular}{|c|c|c|c|c|}
\hline & & \multicolumn{2}{|c|}{ Gender } & \multirow[b]{3}{*}{$\mathbf{P}$} \\
\hline & & $\mathbf{M}$ & $\mathbf{F}$ & \\
\hline & & MUSCLE fat avg & MUSCLE fat avg & \\
\hline \multirow{5}{*}{ Age group } & $20-29$ & $1.58 \pm 0.49$ & $3.34 \pm 1.69$ & $0.010^{*}$ \\
\hline & $30-39$ & $2.77 \pm 1.69$ & $3.56 \pm 2.58$ & 0.488 \\
\hline & $40-49$ & $3.69 \pm 1.44$ & $3.95 \pm 1.84$ & 0.758 \\
\hline & $>=50$ & $4.62 \pm 1.87$ & $6.15 \pm 2.41$ & 0.208 \\
\hline & $\mathrm{P}$ & $0.003^{*}$ & 0.083 & \\
\hline
\end{tabular}

Mean muscular PDFF value in all ages between 20-62 years was $4.14 \pm 2.25$ and $3.22 \pm 1.8$, respectively, for women and men. According to muscular PDFF values, muscle fat content was higher in women than men only in the 20-29 age range and was statistically significant ( $p=0.010$ ) (Table 4). Whereas, muscle fat content was correlated with age in men $(r=0.697, p=0.027)$ (Figure 3).

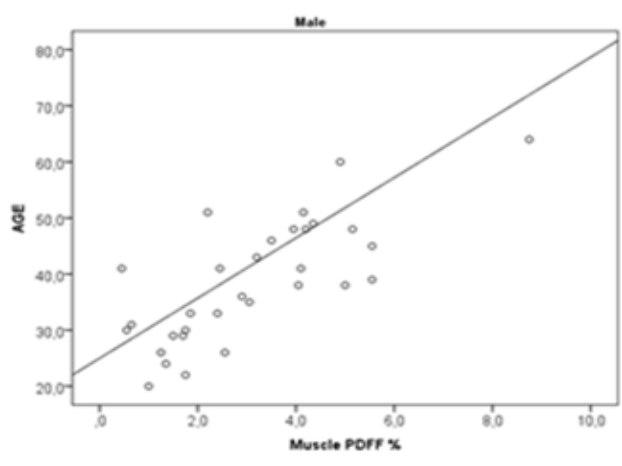

a)

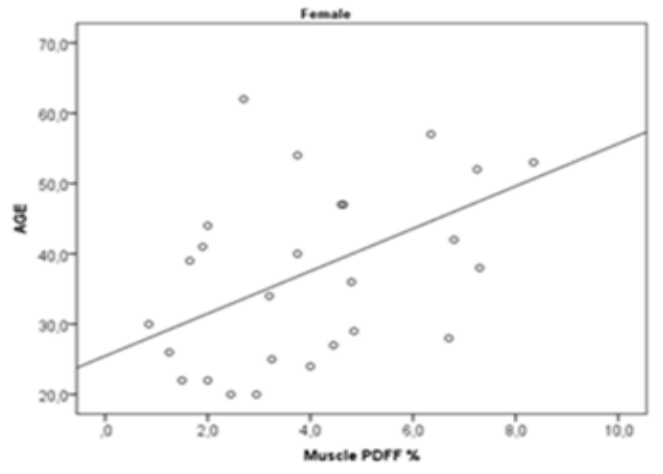

b)

Figure 3: Correlation between age groups and muscular PDFF \% in a) men and b) women

Table 5: Mean hepatic T2* times (msec) based on age groups and gender

\begin{tabular}{|c|c|c|c|c|}
\hline & & \multicolumn{2}{|c|}{ Gender } & \multirow[b]{3}{*}{$\mathbf{P}$} \\
\hline & & $\mathbf{M}$ & $\mathbf{F}$ & \\
\hline & & LIVER FE avg & LIVER FE avg & \\
\hline \multirow{5}{*}{ Age group } & $20-29$ & $23.91 \pm 2.44$ & $25.09 \pm 5.37$ & 0.598 \\
\hline & $30-39$ & $21.90 \pm 1.91$ & $21.52 \pm 2.11$ & 0.727 \\
\hline & $40-49$ & $24.62 \pm 3.02$ & $23.05 \pm 2.23$ & 0.291 \\
\hline & $>=50$ & $22.42 \pm 2.91$ & $22.90 \pm 2.91$ & 0.766 \\
\hline & $\mathrm{P}$ & 0.104 & 0.380 & \\
\hline
\end{tabular}

The mean hepatic T2* times (msec) in all ages between $20-62$ years was $23.49 \pm 3.89$ for women and $23.2 \pm 2.75 \mathrm{msec}$ for men. The Hepatic T2* times did not show a statistically significant difference based on gender and age $(p=0.826)($ Table 5). A mild negative correlation $(r=-0,420, p=0.029)$ and a strong negative correlation $(\mathrm{r}=-0,617, \mathrm{p}=0.001)$ were seen in women and men, respectively, in terms of mean fat content and iron signal time of liver (Figure 4). 


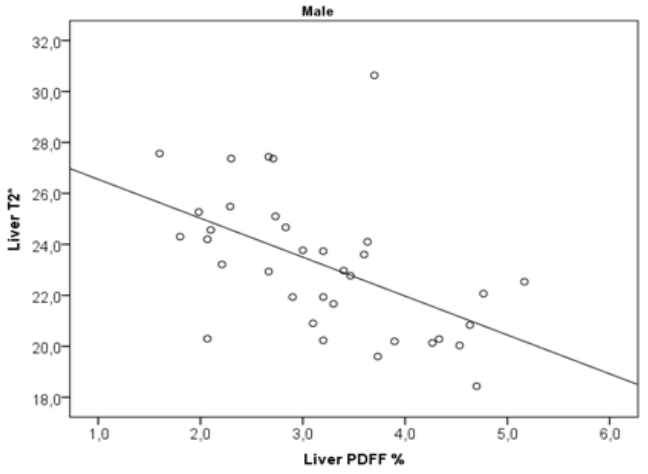

a)

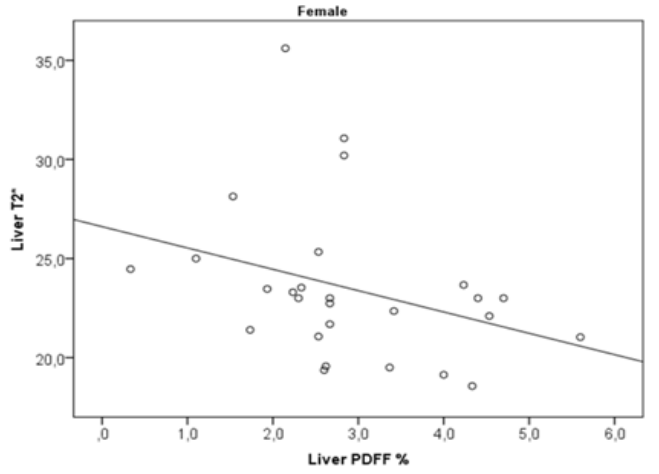

b)

Figure 4: Correlation between hepatic PDFF $\%$ and liver T2* in a) men and b) women

Along with BMI values within normal range in our study group, BMI was found to have a positive weak correlation with liver ( $\mathrm{r}=0.382$, $\mathrm{p}=0.024)$ and muscle fat contents $(\mathrm{r}=0.380, \mathrm{p}=0.024)$ only in men. Also, there was a mild positive correlation between liver fat content and muscle fat content only in men $(r=0.409, p=0.015)$.
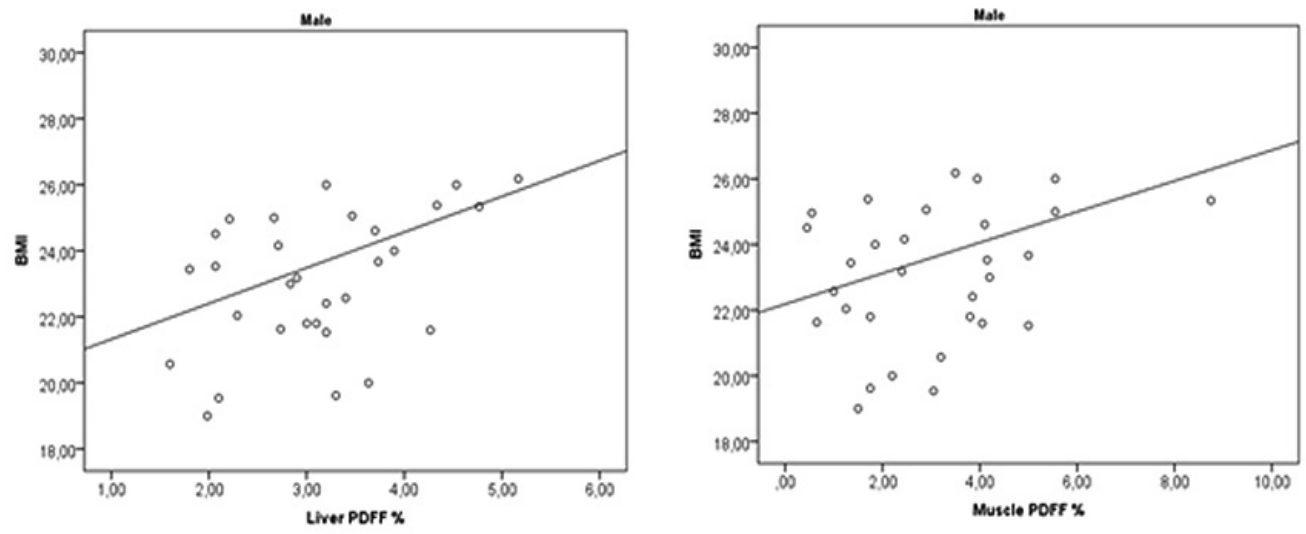

Figure 5: Correlation between a) BMI and hepatic PDFF \% and b) BMI and muscular PDFF \% in men

\section{Discussion}

This is a study on the calculation of hepatic fat and iron content and pancreatic and muscular fat content in a healthy group with varying ages (20-62 years) and gender by using the mDIXON method. Such data have critical importance for DIXONbased quantifications of liver fat and iron as well as pancreatic and muscular fat in future clinical routine. In order to perform a risk assessment in patients with suspected liver disease, it is necessary to distinguish high liver fat content from age-related normal increase. Studies are ongoing with great effort on the direct conversion of MR imaging-derived fat-signal fractions to actual fat content, e.g. as fat in milligram per gram liver tissue. Today, liver fat content is often quantified through histopathological analysis of tissue obtained through liver biopsy [7]. As they are invasive, biopsies are rarely performed in healthy individuals without clinical indications [8], and histological analysis of liver fat content in a healthy population could not be obtained so far due to ethical reasons. Evaluation of visual biopsy is typically based on cell counts and may lead to fat content estimations that are higher than volumetric measurements [14]. Assessment with digital image analysis and computer-assisted morphometry estimates fat content better than the assessments that are based on typical cell count $[15,16]$. Traditionally, fat amount above 50 $\mathrm{mg} / \mathrm{g}$ ( $5 \%$ by wet weight) is accepted as hepatic steatosis [14].

Localized proton magnetic resonance spectroscopy (MRS) is also a non-invasive method that has the potential to measure hepatic triglyceride content accurately $[17,19]$. However, in case of non-homogenous liver tissue, MRS causes sampling errors similar to biopsy. Today, MR Imaging is used as a new gold standard as it is able to quantify intrahepatic fat content in the liver with high accuracy $[20,21]$. Unlike biopsies, this method is non-invasive and presents a representative assessment of the entire liver. 

Magnetic Resonance Imaging

In a large study with broad participation, 95\% of 345 participants who had normal BMI and no risk for fatty liver disease had less than $5.56 \%$ hepatic fat by weight with a minimum of $1.9 \%$ of tissue by weight, in MRS [22]. These values seem compliant with our PDFF values in healthy volunteers with $2.9 \pm 1.2 \%$ in women and $3.19 \pm 0.94 \%$ in men as mean hepatic PDFF values. Studies on patients with chronic hepatitis $\mathrm{C}$ who had their biopsies before therapeutic trials showed a correlation between BMI and liver steatosis [23]. However, liver steatosis did not show a significant correlation with BMI in patients with chronic hepatitis B [24]. Hines et al. [25] reported an exponential relationship between MR fat-signal fraction and BMI with IDEAL algorithm. In a study reported by Gallagher et al. [26], percentages of healthy body fat (measured with dual-energy $\mathrm{X}$-ray absorptiometry) increased with age in both genders. In our study, there was a weak correlation between BMI and liver and a strong correlation between BMI and muscle fat-signal fraction in men whereas we could not find any correlations in women; however, our healthy population included only those with normal BMI.

In recent years, several MR studies have been conducted for liver fat quantification using the modified DIXON method. These studies have found fat-signal rates calculated with MR imaging and MR spectroscopy to be correlated with histopathological examinations [19, 27, 28]. DIXON method enables the onset of transverse magnetization of fat and water protons in diverse frequencies depending on echo-time allowing for separation of signal components (chemical shift), calculation of wateronly and fat-only images, and accordingly, [29], calculation of fat-signal fraction [30]. Typically, minimum two echoes are required for imaging-based fat-water separation with better detection depending on concomitant shortening of transverse magnetization or increased tissue-iron content in more echoes allowing for improved correction of effects such as $\mathrm{T} 1$ suppression due to longer TR, B0-field distortion or T2* [31]. In a recent study [16], mean PDFF values were ranging from 5 to $26 \%$ (mean 8.3 $\pm 6.2 \%$ ) in correlation with histopathologic hepatosteatosis in patients without underlying liver diseases such as liver cirrhosis and hemosiderosis. In another study [32], measurement of PDFF values ranged from 0 to 23 (mean $5.72 \pm 6.03 \%$ ) and 0.54 to $36.45(5.71 \pm 9.00 \%)$, respectively, in women and men. In our study, PDFF value of all cases (with normal BMI) ranged from 0.3 to $5.6 \%$ (mean $2.9 \pm 1.2 \%$ ) and 1.6 to $5.2 \%$ (mean $3.19 \pm 0.94 \%$ ), respectively, in women and men. Our study chose completely healthy individuals, and PDFF value of our group was lower than that in the recent studies conducted with patients [16, 32]. Each histological steatosis degree in NAFLD (non-alcoholic fatty liver disease) was defined as follows: grade 0 (normal): $<5 \%$; grade 1 (mild): 5 to $33 \%$; grade 2 (moderate): 34 to $66 \%$; and grade 3 (severe): $>66 \%$ [33]. PDFF value intervals recommended in MR examinations are as follows: grade 0 (normal) [0-5\%]; grade 1 (mild) [6.5-17.4\%]; grade 2 (moderate) [17.5-22.1\%] and grade 3 (severe) [22.2\% or greater] [34].

In our study, liver iron and muscle iron values were also quantified using the DIXON imaging method. Iron build-up in the liver may be due to hereditary hemochromatosis, transfusionrelated hemochromatosis, chronic hepatopathies, etc. and furthermore, increased oxidative stress-induced exposure over time might result in cirrhosis, liver failure and hepatocellular carcinoma by damaging the liver. Like in steatosis, non-invasive detection of this build-up in the liver might relieve the patient of biopsy which is an invasive process. Among recent studies primarily comparing iron build-up in thalassemia patients with histopathological results and blood ferritin levels, a study on age-related iron build-up in a normal healthy individual would give information about metabolic progression of the patient. A normal liver has longer $\mathrm{T} 2 *$ relaxation time (greater than 20 msec for $1.5 \mathrm{~T}$ ). It can detect the existing hepatic iron build-up at high accuracy with a strong negative correlation between liver T2* values and histological iron grade [35]. Pre-published data demonstrate a relationship between iron build-up and the presence of hepatic inflammation and fibrosis $[36,37]$. Studies in the recent years reveal that $\mathrm{T} 2 *$ values have been measured to be lower particularly in the presence of steatosis [38, 39]. Besides falling within normal limits in a similar way, our study also showed that $2_{2}^{*}$ values decreased as PDFF value increased $(\mathrm{p}=0.029$ in women vs. $\mathrm{p}=0.001$ in men). The reason is the fact that signal loss due to fat-water signal overlap in the first echo might mask or even dominate $\mathrm{T} 2 *$ signal reduction in the second echo [40]. Moreover, upper limit is below $1.5 \mathrm{~T}$ in $3 \mathrm{~T}$ devices depending on rapid signal transmission in the studies [41]. Therefore, despite the insufficient number of patients in our study, T2* ranges from 18.6 to $35.6 \mathrm{msec}$ and from 18.4 to $30.6 \mathrm{msec}$ in women and men, respectively. In this case, values below $20 \mathrm{msec}$ as defined for $1.5 \mathrm{~T}$ might also be considered normal for $3 \mathrm{~T}$. However, more patients should be examined for this lower limit.

Larger studies on pancreatic fat content involving more participants report inconsistent results for the relationship between pancreatic fat content and impaired glucose metabolism $[42,43]$. An explanation for such heterogeneous results might be different imaging methods that are used in the assessment of pancreatic fat content, including ultrasound, computed tomography (CT) and magnetic resonance imaging (MRI) [42, 44]. Considering its non-ionizable characteristics and display of high soft tissue contrast, MRI may be particularly suitable to comprehend the role of pancreatic fat content [44]. Similarly with the liver, detection of age- and gender-related changes in pancreatic fat content in healthy population will help distinguish age- and gender-related normal results from pathological processes. Pathological processes like diabetes and metabolic diseases which might influence the pancreas of the patients have been excluded from our study, and the lack of insulin value (HOMA) data constitutes a limitation. In our study, while pancreatic fat-signal fraction showed an increase with age only in men as well as a significant difference compared to women in the elderly group, mean muscle fat-signal fraction in women was higher than men with a significant difference compared to men in the younger group. This situation implies that steatosis tends to occur outside the organ in women while the reverse seems to be 
true in men in the healthy normal population. We believe that this situation is rather due to sex hormones.

Our study had certain restrictions. To begin with, histopathological comparison could not be made due to ethical reasons as the study included healthy individuals. No measurement associated with breathing artifacts was performed particularly in the hepatic dome, and segment VI, owing to having highest fat content, was used for localization by taking previous studies as basis for measurements. Furthermore, in pancreas PDFF quantifications, extracellular fat areas might have been accidentally included in the calculations despite all the attention paid, particularly in cases with lower pancreatic volume.

An advantage of MRI protocol is the concomitant measurement of PDFF and T2* values in many organs such as liver, pancreas, heart, kidneys or muscles. Moreover, it allows for the calculation of indices such as total adipose tissue, visceral adipose tissue and abdominal subcutaneous adipose tissue.

\section{Conclusion}

Concomitant fat and iron quantifications in the liver, pancreas and many other solid organs are possible with a single 20 -second breath-hold time by using the mDIXON sequence, and on the contrary to biopsy, a large organ can be completely assessed rather than a small part of it. By presenting a fast picture of a patient's general state of health, such an MRI protocol might assist the clinician to better estimate the risk of long-term organ damage by diabetes, cardiovascular disease, cancer and other diseases by dint of information on age-related normal hepatic and pancreatic fat and iron content.

\section{References}

1. Bellentani S, Bedogni G, Miglioli L, Tiribelli C. The epidemiology of fatty liver. European journal of gastroenterology \& hepatology. 2004;16(11):1087-1093.

2. Browning JD, Szczepaniak LS, Dobbins R, Nuremberg P, Horton JD, Cohen JC, et al. Prevalence of hepatic steatosis in an urban population in the United States: impact of ethnicity. Hepatology. 2004;40(6):1387-1395. DOI: 10.1002/hep.20466

3. Stefan N, Kantartzis K, Haring HU. Causes and metabolic consequences of Fatty liver. Endocrine reviews. 2008;29(7):939960. doi: 10.1210/er.2008-0009

4. Mathur A, Zyromski NJ, Pitt HA, Al-Azzawi H, Walker JJ, Saxena $\mathrm{R}$, et al. Pancreatic steatosis promotes dissemination and lethality of pancreatic cancer. Journal of the American College of Surgeons. 2009;208(5):989-994; discussion 94-6. doi: 10.1016/j. jamcollsurg.2008.12.026

5. Dong Z, Luo Y, Cai H, Zhang Z, Peng Z, Jiang M, et al. Noninvasive fat quantification of the liver and pancreas may provide potential biomarkers of impaired glucose tolerance and type 2 diabetes. Medicine. 2016;95(23):e3858. doi: 10.1097/MD.0000000000003858

6. Macauley M, Percival K, Thelwall PE, Hollingsworth KG, Taylor R. Altered volume, morphology and composition of the pancreas in type 2 diabetes. PloS one. 2015;10(5):e0126825. doi: 10.1371/ journal.pone.0126825
7. Caldwell SH, Crespo DM. The spectrum expanded: cryptogenic cirrhosis and the natural history of non-alcoholic fatty liver disease. Journal of hepatology. 2004;40(4):578-584. DOI: 10.1016/j. jhep.2004.02.013

8. Baffy G, Brunt EM, Caldwell SH. Hepatocellular carcinoma in non-alcoholic fatty liver disease: an emerging menace. Journal of hepatology. 2012;56(6):1384-1391. doi: 10.1016/j.jhep.2011.10.027

9. Clavien PA, Petrowsky H, DeOliveira ML, Graf R. Strategies for safer liver surgery and partial liver transplantation. The New England journal of medicine. 2007;356(15):1545-1559. DOI: 10.1056/ NEJMra065156

10. Buxton RB, Wismer GL, Brady TJ, Rosen BR. Quantitative proton chemical-shift imaging. Magnetic resonance in medicine: official journal of the Society of Magnetic Resonance in Medicine / Society of Magnetic Resonance in Medicine. 1986;3(6):881-900. Doi: 10.1002/mrm.1910030609

11. Hussain HK, Chenevert TL, Londy FJ, Gulani V, Swanson SD, McKenna BJ, et al. Hepatic fat fraction: MR imaging for quantitative measurement and display-early experience. Radiology. 2005;237(3):1048-1055. DOI: 10.1148/radiol.2373041639

12.Borra RJ, Salo S, Dean K, Lautamaki R, Nuutila P, Komu M, et al. Nonalcoholic fatty liver disease: rapid evaluation of liver fat content with in-phase and out-of-phase MR imaging. Radiology. 2009;250(1):130-136. doi: 10.1148/radiol.2501071934

13.d'Assignies G, Ruel M, Khiat A, Lepanto L, Chagnon M, Kauffmann $C$, et al. Noninvasive quantitation of human liver steatosis using magnetic resonance and bioassay methods. European radiology. 2009;19(8):2033-2040. doi: 10.1007/s00330-009-1351-4

14. Tannapfel A, Denk H, Dienes HP, Langner C, Schirmacher P, Trauner $\mathrm{M}$, et al. [Histopathological diagnosis of non-alcoholic and alcoholic fatty liver disease. Grade 2 consensus-based guidelines]. Der Pathologe. 2010;31(3):225-237. doi: 10.1007/s00292-010-1274-5

15. Hall AR, Dhillon AP, Green AC, Ferrell L, Crawford JM, Alves V, et al. Hepatic steatosis estimated microscopically versus digital image analysis. Liver international: official journal of the International Association for the Study of the Liver. 2013;33(6):926-935. doi: 10.1111/liv.12162

16. Fischer MA, Nanz D, Reiner CS, Montani M, Breitenstein S, Leschka S, et al. Diagnostic performance and accuracy of 3-D spoiled gradientdual-echo MRI with water- and fat-signal separation in liver-fat quantification: comparison to liver biopsy. Investigative radiology. 2010;45(8):465-470. doi: 10.1097/RLI.0b013e3181da1343

17. Thomsen $C$, Becker $U$, Winkler $K$, Christoffersen $P$, Jensen $M$, Henriksen 0. Quantification of liver fat using magnetic resonance spectroscopy. Magnetic resonance imaging. 1994;12(3):487-495.

18. Cowin GJ, Jonsson JR, Bauer JD, Ash S, Ali A, Osland EJ, et al. Magnetic resonance imaging and spectroscopy for monitoring liver steatosis. Journal of magnetic resonance imaging: JMRI. 2008;28(4):937-945. doi: 10.1002/jmri.21542

19. Longo R, Pollesello P, Ricci C, Masutti F, Kvam BJ, Bercich L, et al. Proton MR spectroscopy in quantitative in vivo determination of fat content in human liver steatosis. Journal of magnetic resonance imaging: JMRI. 1995;5(3):281-285. 
20. Fischer MA, Raptis DA, Montani M, Graf R, Clavien PA, Nanz D, et al. Liver fat quantification by dual-echo MR imaging outperforms traditional histopathological analysis. Academic radiology. 2012;19(10):1208-1214. doi: 10.1016/j.acra.2012.05.009

21. Raptis DA, Fischer MA, Graf R, Nanz D, Weber A, Moritz W, et al. MRI: the new reference standard in quantifying hepatic steatosis? Gut. 2012;61(1):117-127. doi: 10.1136/gutjnl-2011-300155

22.Szczepaniak LS, Nurenberg P, Leonard D, Browning JD, Reingold JS, Grundy S, et al. Magnetic resonance spectroscopy to measure hepatic triglyceride content: prevalence of hepatic steatosis in the general population. American journal of physiology Endocrinology and metabolism. 2005;288(2):E462- E468. DOI: 10.1152/ ajpendo.00064.2004

23.Conjeevaram HS, Kleiner DE, Everhart JE, Hoofnagle JH, Zacks S, Afdhal NH, et al. Race, insulin resistance and hepatic steatosis in chronic hepatitis C. Hepatology. 2007;45(1):80-87. DOI: 10.1002/ hep. 21455

24. Ayhan Balkan, Murat Taner Gülșen, Yasemin Balkan, Seçil Kaya Çalı. Relationship between the frequency of hepatitis B virus infections and levels of serum adipokines in patients with hepatosteatosis and insulin resistance. Eur J Ther. 2017;23: 60-66. DOI: 10.5152/ EurJTher.2017.20

25. Hines CD, Yu H, Shimakawa A, McKenzie CA, Warner TF, Brittain JH, et al. Quantification of hepatic steatosis with 3-T MR imaging: validation in ob/ob mice. Radiology. 2010;254(1):119-128. doi: 10.1148/radiol.09090131

26.Gallagher D, Heymsfield SB, Heo M, Jebb SA, Murgatroyd PR, Sakamoto Y. Healthy percentage body fat ranges: an approach for developing guidelines based on body mass index. The American journal of clinical nutrition. 2000;72(3):694-701. DOI: 10.1093/ ajcn/72.3.694

27. Yokoo T, Bydder M, Hamilton G, Middleton MS, Gamst AC, Wolfson T, et al. Nonalcoholic fatty liver disease: diagnostic and fat-grading accuracy of low-flip-angle multiecho gradient-recalled-echo MR imaging at 1.5 T. Radiology. 2009;251(1):67-76. doi: 10.1148/ radiol. 2511080666

28. Kim H, Taksali SE, Dufour S, Befroy D, Goodman TR, Petersen KF, et al. Comparative MR study of hepatic fat quantification using singlevoxel proton spectroscopy, two-point dixon and three-point IDEAL. Magnetic resonance in medicine: official journal of the Society of Magnetic Resonance in Medicine / Society of Magnetic Resonance in Medicine. 2008;59(3):521-527. doi: 10.1002/mrm.21561

29. Ma J. Dixon techniques for water and fat imaging. Journal of magnetic resonance imaging: JMRI. 2008;28(3):543-558. doi: 10.1002/jmri.21492

30.Cassidy FH, Yokoo T, Aganovic L, Hanna RF, Bydder M, Middleton MS, et al. Fatty liver disease: MR imaging techniques for the detection and quantification of liver steatosis. Radiographics: a review publication of the Radiological Society of North America, Inc. 2009;29(1):231-260. doi: 10.1148/rg.291075123

31. Alabousi A, Al-Attar S, Joy TR, Hegele RA, McKenzie CA. Evaluation of adipose tissue volume quantification with IDEAL fat-water separation. Journal of magnetic resonance imaging: JMRI. 2011;34(2):474-479. doi: 10.1002/jmri.22603
32.Fischer MA, Donati OF, Chuck N, Blume IN, Hunziker R, Alkadhi H, et al. Two- versus three-dimensional dual gradient-echo MRI of the liver: a technical comparison. European radiology. 2013;23(2):408416. doi: 10.1007/s00330-012-2614-z

33. KleinerDE, BruntEM, Van NattaM, BehlingC, Contos MJ,Cummings OW, Ferrell LD, et al. Design and validation of a histological scoring system for nonalcoholic fatty liver disease. Hepatology. 2005;41(6):13131321. DOI: $10.1002 /$ hep. 20701

34.Tang A, Tan J, Sun M, Hamilton G, Bydder M, Wolfson T, et al. Nonalcoholic Fatty Liver Disease: MR Imaging of Liver Proton Density Fat Fraction to Assess Hepatic Steatosis. Radiology. 2013;267(2):422-431. doi: 10.1148/radiol.12120896

35.Beaumont M, Odame I, Babyn PS, Vidarsson L, Kirby-Allen M, Cheng HL. Accurate liver T2 measurement of iron overload: a simulations investigation and in vivo study. J Magn Reson Imaging 2009;30(2):313-320. doi: 10.1002/jmri.21835

36. Martinelli AL, Filho AB, Franco RF, Tavella MH, Ramalho LN, Zucoloto $S$ et al. Liver iron deposits in hepatitis B patients: association with severity of liver disease but not with hemochromatosis gene mutations. J Gastroenterol Hepatol 2004;19(9):1036-1041. DOI: 10.1111/j.1440-1746.2004.03410.x

37. Beinker NK, Voigt MD, Arendse M, Smit J, Stander IA, Kirsch RE. Threshold effect of liver iron content on hepatic inflammation and fibrosis in hepatitis B and C. J Hepatol 1996;25(5):633-638.

38.Gandon Y, Guyader D, Heautot JF, et al. Hemochromatosis: diagnosis and quantification of liver iron with gradient-echo MR imaging. Radiology. 1994;193(2):533-538. DOI: 10.1148/ radiology.193.2.7972774

39. O'Regan DP, Callaghan MF, Wylezinska-Arridge M, Fitzpatrick J, Naoumova RP, Hajnal JV et al. Liver fat content and T2*: simultaneous measurement by using breath-hold multiecho MR imaging at 3.0 T--feasibility. Radiology. 2008;247(2):550-557. doi: 10.1148/radiol.2472070880

40.Westphalen AC, Qayyum A, Yeh BM, Merriman RB, Lee JA, Lamba A, et al. Liver fat: effect of hepatic iron deposition on evaluation with opposed-phase MR imaging. Radiology. 2007;242(2):450-455. DOI: 10.1148/radiol.2422052024

41.Wood JC. Magnetic resonance imaging measurement of iron overload. Curr Opin Hematol. 2007;14(3):183-190. DOI: 10.1097/ MOH.0b013e3280d2b76b

42. Kuhn JP, Berthold F, Mayerle J, Volzke H, Reeder SB, Rathmann W, et al. Pancreatic Steatosis Demonstrated at MR Imaging in the General Population: Clinical Relevance. Radiology. 2015;276(1):129-136. doi: 10.1148/radiol.15140446

43.Ou HY, Wang CY, Yang YC, Chen MF, Chang CJ. The association between nonalcoholic fatty pancreas disease and diabetes. PloS one. 2013;8(5):e62561. doi: 10.1371/journal.pone.0062561

44.Idilman IS, Tuzun A, Savas B, Elhan AH, Celik A, Idilman R, et al. Quantification of liver, pancreas, kidney, and vertebral body MRI-PDFF in non-alcoholic fatty liver disease. Abdominal imaging. 2015;40(6):1512-1519. doi: 10.1007/s00261-015-0385-0 